\title{
Mesenchymal stem cells for cartilage repair in osteoarthritis
}

\author{
Pawan K Gupta', Anjan K Das², Anoop Chullikana' and Anish S Majumdar*1
}

\begin{abstract}
Osteoarthritis $(\mathrm{OA})$ is a degenerative disease of the connective tissue and progresses with age in the older population or develops in young athletes following sports-related injury. The articular cartilage is especially vulnerable to damage and has poor potential for regeneration because of the absence of vasculature within the tissue. Normal load-bearing capacity and biomechanical properties of thinning cartilage are severely compromised during the course of disease progression. Although surgical and pharmaceutical interventions are currently available for treating OA, restoration of normal cartilage function has been difficult to achieve. Since the tissue is composed primarily of chondrocytes distributed in a specialized extracellular matrix bed, bone marrow stromal cells (BMSCs), also known as bone marrow-derived 'mesenchymal stem cells' or 'mesenchymal stromal cells', with inherent chondrogenic differentiation potential appear to be ideally suited for therapeutic use in cartilage regeneration. BMSCs can be easily isolated and massively expanded in culture in an undifferentiated state for therapeutic use. Owing to their potential to modulate local microenvironment via anti-inflammatory and immunosuppressive functions, BMSCs have an additional advantage for allogeneic application. Moreover, by secreting various bioactive soluble factors, BMSCs can protect the cartilage from further tissue destruction and facilitate regeneration of the remaining progenitor cells in situ. This review broadly describes the advances made during the last several years in BMSCs and their therapeutic potential for repairing cartilage damage in $\mathrm{OA}$.
\end{abstract}

${ }^{*}$ Correspondence: anish.majumdar@stempeutics.com

'Stempeutics Research Private Limited, Akshay Tech Park, Whitefield, Bangalore 560066, India

Full list of author information is available at the end of the article

\section{Introduction}

The knee joint is a marvel of engineering that acts as a conduit for transferring the weight of the body and also enables sophisticated movements that are essential for normal human mobility. Normal joint movements depend upon the anatomical structures of the tissue. This also helps perfoming physiological functions that the joint cartilage and synovial membrane carry out to enable smooth functioning of the tissue. The cartilage is a highly specialized structure that is composed predominantly of extracellular matrix (ECM) and an aggregate-forming proteoglycan, aggrecan, with embedded chondrocytes [1]. The main structural feature contributing to the whitish glassy appearance of the tissue is due to the ECM known as hyaline cartilage [2]. The ECM is composed of a dense framework of collagen fibers of mainly type II with small amounts of other subtypes of collagen. This unique biomechanical and structural composition of cartilage enables the tissue to balance its mechanical sturdiness and flexibility that are essential for normal tissue function.

Osteoarthritis (OA) has a direct effect on the functioning of several joints, of which the knee is the most important clinically. It has been estimated that all individuals above the age of 65 will have some clinical or radiographic evidence of OA. The basic pathophysiological feature of OA is a loss of articular cartilage, although multiple components of the joint, including bone and synovial membrane, may also be affected [3]. The chondrocyte, which is the principal cellular component of the cartilage, is a relatively inert cell and has little regenerative capacity. While some regeneration does take place in childhood, this ability is lost with age and is almost completely absent after 60 years or more. In addition, complex molecular mechanisms, including the secretion of proteolytic enzymes, further degrade the diseased cartilage. These enzymes include aggrecanases and metalloproteineases and are mediated by interleukin 1 as well as by tumor necrosis factor-alpha [4]. Figure 1 describes the major pathological and biochemical features that ultimately lead to OA.

\section{Current treatment for osteoarthritis}

Mild cases of OA can be treated with a combination of non-pharmacologic (for example, physiotherapy) and 


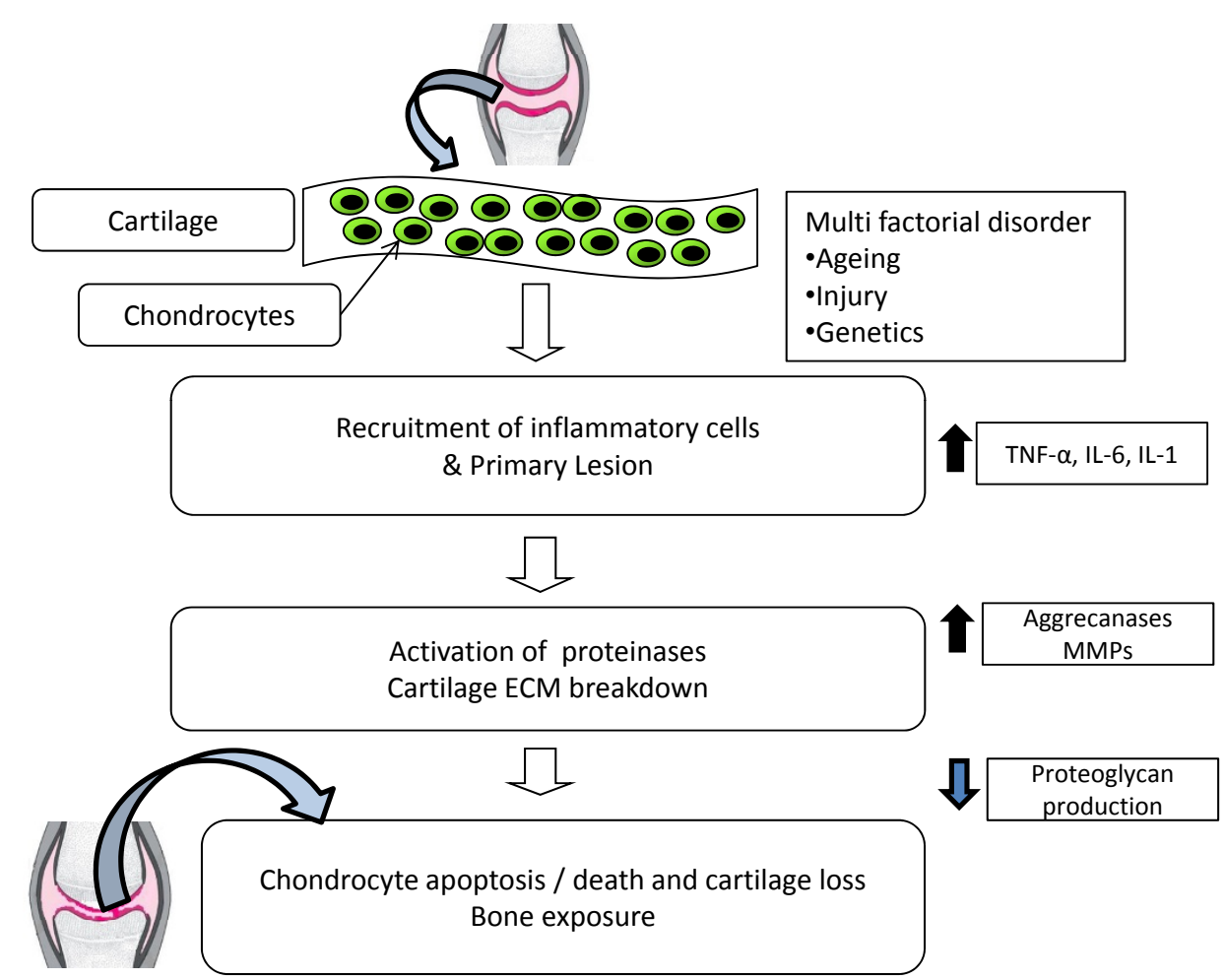

Figure 1. Pathogenesis of osteoarthritis. Osteoarthritis is a progressively degenerative disease of multiple etiology in which injury and aging lead to gradual breakdown of articular cartilage. The pathogenesis is categorized by severe inflammation, recruitment of inflammatory cells, proinflammatory cytokine production, and activation of proteinases that results in extracellular matrix (ECM) degradation and ultimately apoptotic cell death of differentiated chondrocytes. IL, interleukin; MMP, matrix metalloproteinase; TNF-a, tumor necrosis factor-alpha.

pharmacologic agents to reduce pain and inflammation. However, as the disease progresses, additional aggressive treatments are required and these may include the use of intra-articular steroids (Hycort) or hyaluronic acid (Hyalgan) administration [4]. Although some patients experience temporary relief, the efficacy of these interventions is not uniform and there is some debate about their effectiveness. In more advanced or severe cases of $\mathrm{OA}$, knee replacement is the only viable therapeutic option [5].

It has been suggested that many of the mechanisms that cause the symptoms and pathophysiology of OA can be reversed by the application of cell-based therapies [6]. The use of cultured autologous chondrocytes for cartilage regeneration has been used successfully for over a decade $[7,8]$. However, this technique necessitates cartilage biopsy, which is an invasive procedure, and the early promise of this technique has not been borne out in carefully conducted clinical trials. In addition, chondrocytes obtained from the donor site have been shown to de-differentiate during culture expansion with concomitant downregulation of cartilage-specific genes and limited life span following transplantation [9]. This has left the field open to other therapies and the most promising of these are bone marrow stromal cells (BMSCs) to repair the damaged tissue.

\section{Mesenchymal stem cells and chrondrogenesis}

Several varieties of stem cells, including BMSCs in particular, have been shown to differentiate in the presence of appropriate growth stimuli, along specific pathways for producing cartilage tissue. Mesenchymal stem cells (MSCs) have been isolated first from the bone marrow [10] and subsequently from a variety of other tissues such as adipose tissue, placenta, umbilical cord and cord blood, dental pulp, and amnion. However, the ability of MSCs isolated from these tissues to form cartilage is currently being examined rigorously [11]. MSCs or MSClike cells are believed to replace cells lost due to aging or tissue injury. MSCs are usually isolated by their plastic adherence property and can be expanded in large-scale culture for clinical use. Although no specific marker has been identified to isolate the MSC population, the International Society of Cell Therapy has defined these cells to be positive for stromal cell markers CD73, $\mathrm{CD} 105$, and $\mathrm{CD} 90$ and negative for hematopoietic 


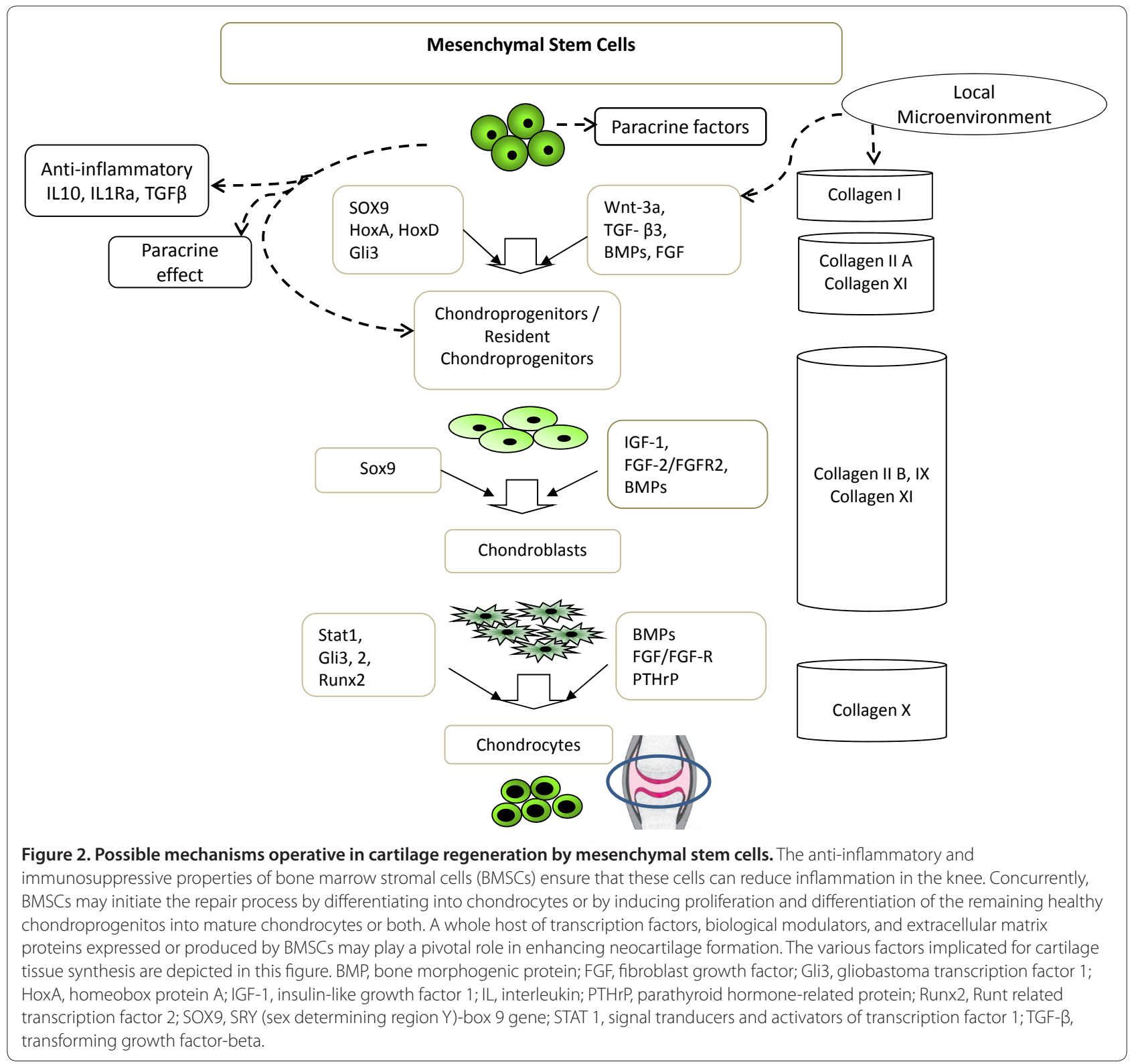

markers (CD45, CD34, CD14, CD19, CD11b, and HLADR) [12]. The lack of a specific marker to identify MSCs has made it difficult to categorically determine the similarities or differences between the biological properties of these cells isolated from various tissue types. Interestingly, BMSCs have been shown to possess several unique biological properties that are potentially beneficial for their use in both autologous and allogeneic cell therapy. Their intrinsic self-renewing ability and differentiation potential into chondrocytes, adipocytes, and osteocytes have been well documented $[13,14]$.

Chondrogenic differentiation of BMSCs is a complex interactive network between transcriptional factors, extracellular growth factors, and signal transduction pathways $[15,16]$ (Figure 2). The intrinsic chondrogenic differentiation potential of BMSCs is believed to be controlled by transcription factors sox-9 and runx-2, whereas transforming growth factor (TGF), like TGF- $\beta 3$, as well as bone morphogenic proteins are some of the most potent inducers of BMSC chondrogenesis $[17,18]$. Recently, Weiss and colleagues [19] showed that parathyroid hormone-like peptide and basic fibroblast growth factor play a critical role in regulating terminal differentiation of BMSCs by suppressing collagen $\mathrm{X}$ while maintaining the expression of other matrix protein, thus preventing hypertrophic differentiation of BMSCs by in vitro pellet cultures. A comparative study using MSCs obtained from various tissue sources reported that 
synovium-derived MSCs exhibited maximum chondrogenesis potential followed by bone marrow-derived MSCs [20]. These results suggest that bone marrowderived MSCs can be used as a cell source for cartilage repair, although the mechanism of hypertrophic differentiation of MSC-derived cartilaginous structures to bone after transplantation remains to be elucidated [19].

MSCs isolated from bone marrow and adipose tissue and loaded on a three-dimensional scaffold under appropriate differentiation cues can acquire chondrogenic phenotype, and the resulting construct can be used as replacement tissue for cartilage repair [21-25]. Several comparative studies have shown that the quality of cartilage produced by using bone marrow-derived stromal cells is substantially lower than that obtained by using chondrocytes. In a recent study, micron-sized fibers, produced by the electro-spinning technique, were shown to provide a structure and properties comparable to those of the cartilage ECM and to enhance chondrogenesis of BMSCs [26]. Researchers are also making efforts to improve scaffolds by combining BMSCs with several biomaterials such as poly-lactic-co-glycolic acid sponge and fibrin gel along with TGF- $\beta 1$ with satisfactory results [27]. In another study, investigators used human MSCs incubated in vitro with TGF- $\beta 3$-releasing fibronectin-coated pharmacologically active microcarriers (PAMs) in chondrogenic medium, and these cells firmly adhered to the surface of PAMs and rapidly form cell aggregates [28]. After three weeks, strong upregulation of cartilage-specific markers was observed at both the mRNA and protein levels, whereas osteogenic or adipogenic genes could not be detected. These results provide new insight into chondrocyte differentiation of BMSCs in the presence of appropriate biomaterials and chondrogenic factors that require in vivo experimentation for cartilage regeneration.

\section{Biology of mesenchymal stem cells}

In addition to having multi-lineage differentiation capacity, multi-potent stromal cells obtained from bone marrow and other tissues possess several properties that are unique to these cells in order to bring about tissue regeneration. In particular, BMSCs are known to preferentially home and accumulate to the site of injury and inflammation. The SDF1/CXCR pathway is a key regulator for BMSC migration, and, in the absence of SDF1 signal, migration of these cells to the bone tissue has been found to be impaired $[29,30]$. These cells are also known to secrete a large number of growth factors, cytokines, and chemokines that carry out different functions. This paracrine activity of MSCs obtained from various sources is thought to be one of the major means by which these cells mediate anti-inflammatory, anti-apoptotic, antifibrotic, angiogenic, mitogenic, and wound-healing properties [31]. The complex interplay of some of these biological mediators secreted by MSCs has been shown to be important in regulating regeneration of a variety of damaged or diseased organs of the body, although complete clarity with respect to the secretome profile of MSCs obtained from different tissues and their specific functions still requires extensive investigations [32].

\section{Immunomodulatory properties of mesenchymal stem cells}

One of the key characteristics of MSCs, regardless of the organs from which they are isolated, is that these cells are generally hypoimmunogenic and possess immunosuppressive activity, although the mechanism of immunomodulation may not be same between different types of MSCs. As a result, use of MSCs for allogeneic therapy does not require HLA matching [33]. Allogeneic cell therapy often calls for using traditional immunosuppressive medications, but this may not be the case for MSC transplantation. The basis of their hypo- or nonimmunogenic nature is that MSCs express low to intermediate levels of HLA class I antigens and are negative for cell surface expression of HLA class II molecules [33]. Upon treatment with interferon-gamma, BMSCs express HLA class II antigens on the surface; however, this expression was not found to alter the immunomodulatory activity of these cells [34]. In addition, BMSCs have been shown to be negative for costimulatory molecules that are required for alloreactive T-cell stimulation [33,35]. More importantly, chondrocytes, adipocytes, and osteocytes differentiated from human BMSCs have also been shown to be non-immunogenic in nature [33]. Collectively, these results suggest that BMSCs could be used as off-the-shelf product for allogeneic application for cartilage repair.

\section{Preclinical efficacy of mesenchymal stem cells in cartilage regeneration}

The effect of MSC transplantation has also been shown to be effective for cartilage repair in various preclinical models of OA. In an elegant study by Murphy and colleagues [36], autologous BMSCs were suspended in hyaluronan solution and injected intra-articularly in goats in which OA was induced by surgery. Although injected labeled BMSCs were not found in large numbers in the cartilage area, regeneration of the tissue was clearly evident in animals receiving cells in comparison with the control group. Similarly, undifferentiated BMSCs or predifferentiated BMSCs on scaffolds yielded encouraging results in rabbit [37] and sheep [38] models of OA. From these studies, it appears that BMSCs alone or MSCs embedded on biodegradable scaffold have the potential to be therapeutically effective for degenerative diseases, including OA. 


\section{Bone marrow stromal cell-based therapy for cartilage repair}

Several clinical investigators from various parts of the world have reported on the safety and therapeutic effect of BMSC administration in patients with OA (Table 1). Nejadnik and colleagues [39] conducted a study to compare the clinical outcome of patients treated with first-generation autologous chondrocyte implantation $(\mathrm{n}=36)$ with that of patients treated with autologous BMSCs $(\mathrm{n}=36)$. The clinical outcome was measured before and at various time points after operation by using the International Cartilage Repair Society Cartilage Injury Evaluation Package. There was significant improvement in the patients' quality of life after cartilage repair in both groups. However, there was no difference between the BMSCs and the autologous chondrocyte implantation groups in terms of clinical outcome except for physical role functioning, and a greater improvement over time in the BMSC group was observed. The improvement in clinical symptoms observed after cartilage repair using BMSCs in the clinical trial by Nejadnik and colleagues [39] is in agreement with clinical outcomes of earlier studies in which clinical symptoms were reported to have improved and repair of cartilage was detected by histopathological evaluation and magnetic resonance imaging (MRI) techniques [40,41]. In fact, Wakitani and colleagues [41] showed that the defect in one patient had been repaired with fibrocartilaginous tissue after 12 months of cell transplantation. The MRI result obtained from another patient after 12 months revealed complete coverage of the defect, although the nature of the cartiliganeous tissue was not determined. In a separate study, Haleem and colleagues [42] reported that autologous BMSCs placed on platelet-rich fibrin glue when administered into the knee of patients with OA resulted in complete defect fill and surface congruity with the native cartilage in one patient whereas the other two patients showed incomplete congruity. Similarly, Kasemkijwattana and colleagues [43] showed improvement in cartilage regrowth in two BMSC-transplanted patients by arthroscopic assessment, which was accompanied with functional recovery. Studies published by other investigators also demonstrated reduction in pain [44] and some improvement in femoral cartilage volume [45], albeit in a smaller number of patients.

In a phase I/II trial conducted by Osiris Therapeutics, Inc. (Columbia, MD, USA), intra-articular administration of allogeneic BMSCs in patients with OA significantly reduced pain in comparison with the placebo group. This effect was observed in patients receiving a low dose (50 million cells) as well as in patients receiving a high dose (150 million cells) [46]. A recent presentation made by the same group demonstrated consistency in the pain score of BMSC-treated patients two years after the cell administration [47]. However, MRI examination of the treated knee revealed wide variability in the meniscus volume between the cell-treated and the control groups of patients. Thus, it is clearly evident that administration of autologous or allogeneic BMSCs into the knee of patients with $\mathrm{OA}$ is safe and efficacious as far as the pain reduction is concerned, with improvement in articular cartilage regeneration and physical function. It is noteworthy that a clinical study conducted with adipose tissue-derived stem cells along with a low dose of dexamethasone also showed encouraging results in regard to cartilage regeneration and reduced pain score in patients with OA [48].

In a search of the ClinicalTrials.gov website [49] in which the keywords 'osteoarthritis' and 'mesenchymal stem cells' were used, 16 clinical trials in OA could be shortlisted; 14 of these are using either autologous or allogeneic BMSCs, and the remaining two trials are investigating the effect of adipose tissue-derived and umbilical cord blood-derived MSCs. The various investigative parameters of these clinical trials are also summarized in Table 1.

Recently, we initiated two randomized, double-blinded, multi-center, placebo-controlled, dose-finding studies assessing the safety and efficacy of ex vivo-cultured allogeneic BMSCs following intra-articular administration in patients with OA. Our previous clinical data from the same product demonstrated safety of allogeneic BMSCs in patients with critical limb ischemia and acute myocardial infarction (Gupta and colleagues, manuscript in preparation). Considering our safety data and the published clinical trials conducted in $\mathrm{OA}$, we are performing dose-ranging clinical trials in India (NCT01453738) and Malaysia (NCT01448434), where OA is highly prevalent among older men and women. The study in India is being conducted by using four different doses (25, 50, 75, and 150 million) of allogeneic BMSCs, whereas the Malaysia trial involves two doses of cells ( 25 and 50 million). The patients will be followed up for a total of two years by using different efficacy parameters such as WOMAC (Western Ontario and McMaster Universities) Osteoarthritis Index, ICOAP (Intermittent and Constant Osteoarthritis Pain) score, Visual Analogue Score, and radiological evidence of improvement by both $\mathrm{x}$-ray and MRI of affected knee joints. Results obtained from our study as well as from the clinical trials being conducted elsewhere may conclusively determine the efficacy and safety of using BMSCs for the regeneration of cartilage in patients with OA.

\section{Conclusions}

Several important characteristics of BMSCs make them an attractive population of cells for cartilage repair. In particular, BMSCs have been shown to migrate and 


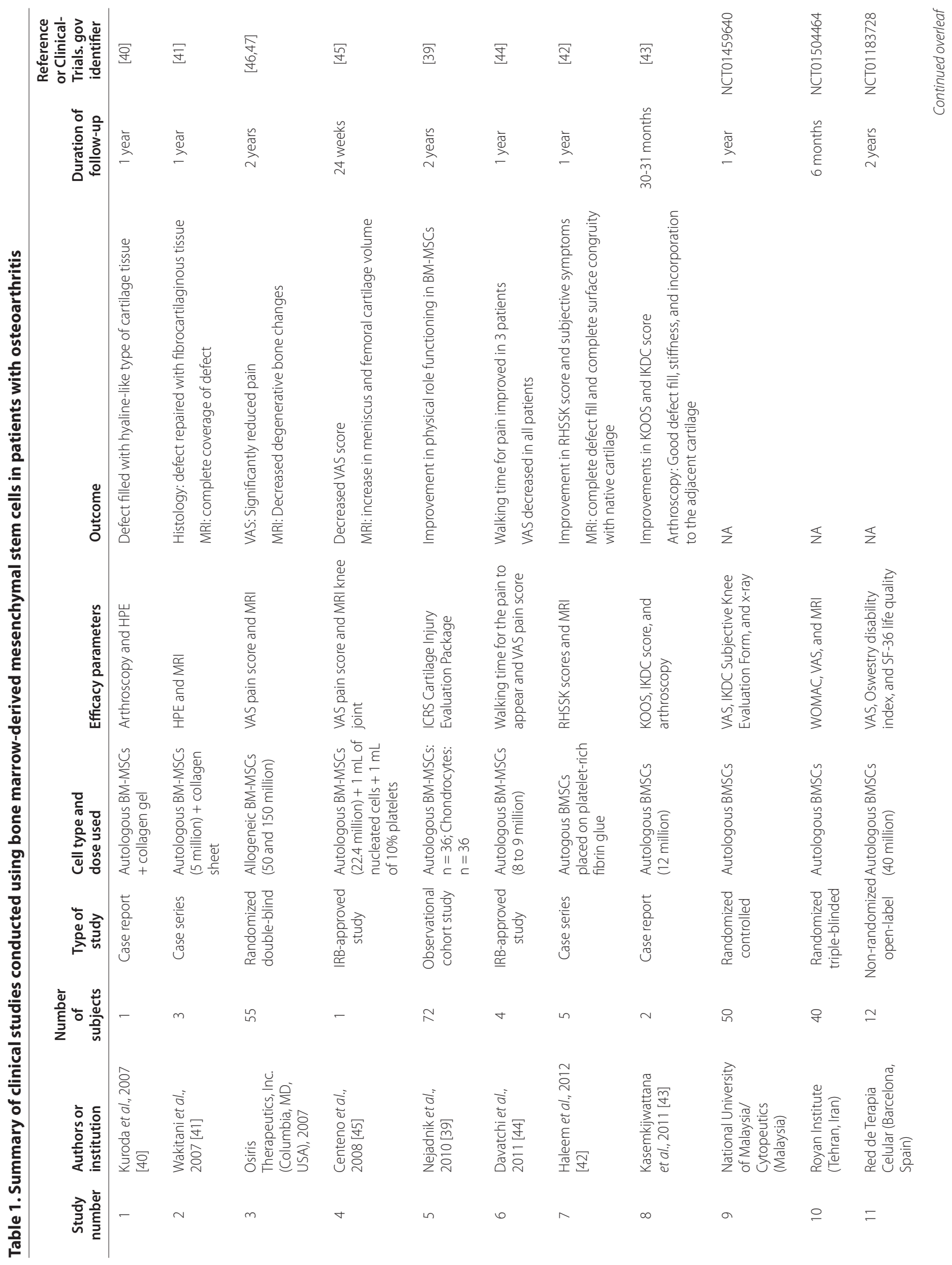




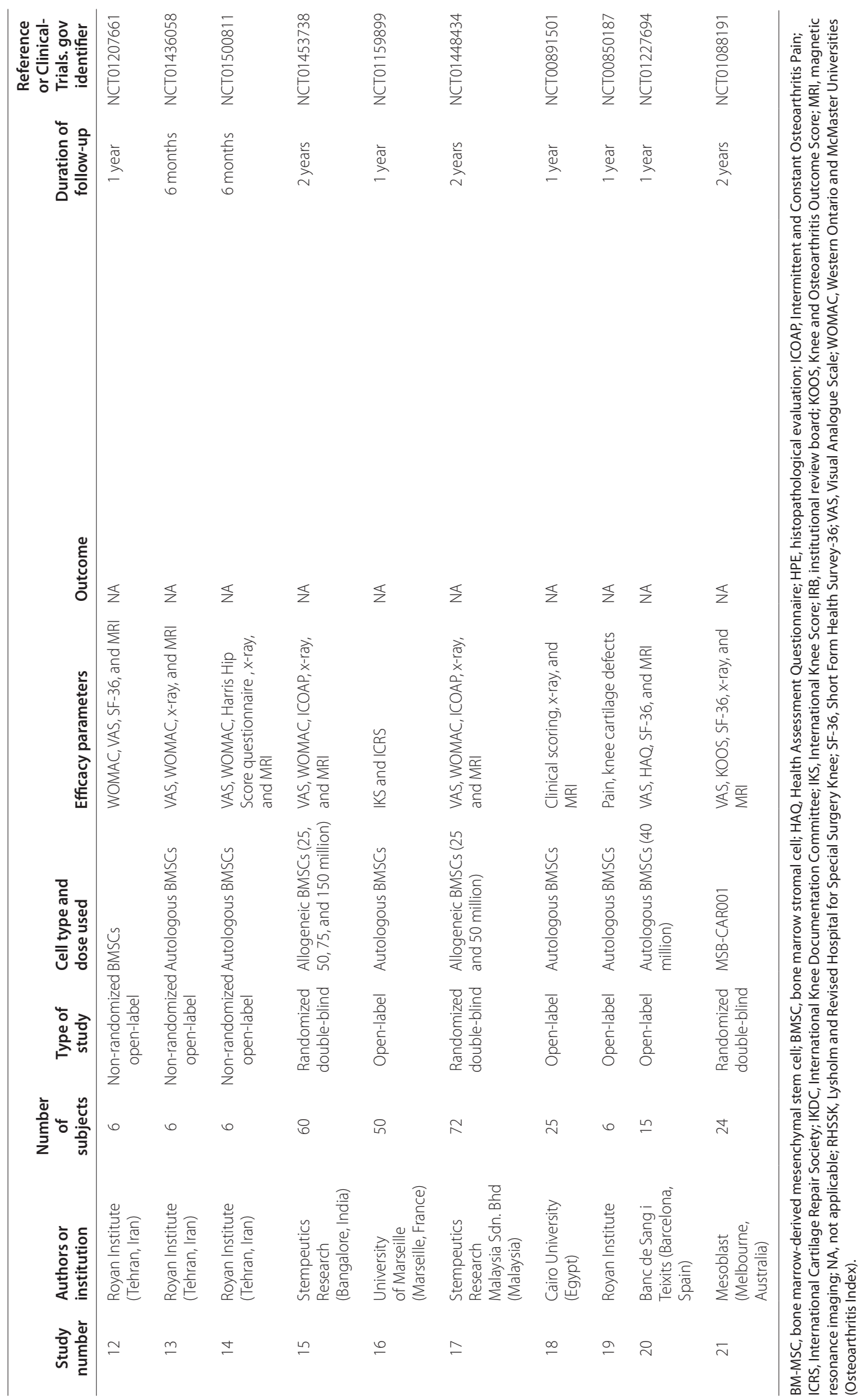


engraft onto multiple musculoskeletal tissues, especially at the site of injury, and undergo tissue-specific differentiation. The anti-inflammatory and immunosuppressive properties of BMSCs ensure that these cells can be used in the context of allogeneic transplantation. Both autologus and allogeneic cell-based therapies using BMSCs for cartilage repair have been shown to produce acceptable clinical results. Although the exact mechanism by which BMSCs are expected to regenerate articular cartilage in patients with OA is not clear, the ability of these cells to induce proliferation and differentiation of resident progenitor cells or their innate differentiation potential to chondrocytes may aid the regeneration of the damaged cartilage. It is also plausible that the combination of paracrine activity and differentiation ability of BMSCs may be operative in vivo to bring about the desired changes in neocartilage formation. Carefully planned clinical trials using BMSCs obtained from patients (autologous) and from normal healthy volunteers (allogeneic) may shed valuable insight into the curative properties and long-term sustenance of these cells in the local microenvironment. Undoubtedly, a great deal of progress is required at both basic and clinical research fronts before these cells can be used routinely in the clinic for treating patients with OA.

This article is part of a thematic series on Clinical applications of stem cells edited by Mahendra Rao. Other articles in the series can be found online at http://stemcellres.com/series/clinical

\section{Abbreviations}

BMSC, bone marrow stromal cell; ECM, extracellular matrix; MRI, magnetic resonance imaging; MSC, mesenchymal stem cell; OA, osteoarthritis; PAM, pharmacologically active microcarrier; TGF, transforming growth factor.

\section{Competing interests}

All authors are employees of Stempeutics Research, and some hold stock options.

\section{Acknowledgments}

The work was supported and funded jointly by Stempeutics Research Private Limited (India) and Stempeutics Research (Malaysia). We thank Balu N Manohar, Sudha Balasubramaniam, and Uday Kumar for critical reading of the manuscript and for providing valuable suggestions.

\section{Author details}

'Stempeutics Research Private Limited, Akshay Tech Park, Whitefield, Bangalore 560066, India. ${ }^{2}$ Stempeutics Research Malaysia Sdn. Bhd., Technology Park, Malaysia 57000 Kuala Lumpur, Malaysia.

Published: 9 July 2012

\section{References}

1. Poole AR: Cartilage in health and disease. In Arthrities and Allied Conditions: A Textbook of Rheumatology. 13th edition. Edited by Koopman WS. Baltimore: Lippincott Williams and Wilkins; 1997:255-308.

2. Hollander AP, Dickinson SC, Kafienah W: Stem cells and cartilage development: complexities of a simple tissue. Stem Cells 2010, 28:1992-1996.

3. Goldring MB, Goldring SR: Articular cartilage and subchondral bone in the pathogenesis of osteoarthritis. Ann N Y Acad Sci 2010, 1192:230-237.
4. Chevalier $X$ : Intraarticular treatments for osteoarthritis: new perspectives. Curr Drug Targets 2012, 11:546-560

5. Buckwalter JA, Saltzman C, Brown T: The impact of osteoarthritis. Clin Orthop Relat Res 2004, 427 (Suppl):6-15.

6. Koelling S, Miosge N: Stem cell therapy for cartilage regeneration in osteoarthritis. Expert Opin Biol Ther 2009, 9:1399-1405.

7. Brittberg M, Lindahl A, Nilsson A, Ohlsson C, Isaksson O, Peterson L: Treatment of deep cartilage defects in the knee with autologous chondrocyte transplantation. N Eng/ J Med 1994, 331:889-895.

8. Peterson L, Minas T, Brittberg M, Nilsson A, Sjögren-Jansson E, Lindahl A: Two- to 9-year outcome after autologous chondrocyte transplantation of the knee. Clin Orthop Relat Res 2000, 374:212-234.

9. Brittberg M, Peterson L, Sjögren-Jansson E, Tallheden T, Lindahl A: Articular cartilage engineering with autologous chondrocyte transplantation. A review of recent developments. J Bone Joint Surg Am 2003, 85-A (Suppl 3):109-115.

10. Friedenstein AJ, Gorskaja JF, Kulagina NN: Fibroblast precursors in normal and irradiated mouse hematopoietic organs. Exp Hematol 1976, 4:267-274.

11. Hass R, Kasper C, Böhm S, Jacobs R: Different populations and sources of human mesenchymal stem cells (MSC): a comparison of adult and neonatal tissue-derived MSC. Cell Commun Signal 2011, 9:12.

12. Dominici M, Le Blanc K, Mueller I, Slaper-Cortenbach I, Marini F, Krause D, Deans R, Keating A, Prockop DJ, Horwitz E: Minimal criteria for defining multipotent mesenchymal stromal cells. The International Society for Cellular Therapy position statement. Cytotherapy 2006, 8:315-317.

13. Prockop DJ: Marrow stromal cells as stem cells for nonhematopoietic tissues. Science 1997, 276:71-74

14. Pittenger MF, Mackay AM, Beck SC, Jaiswal RK, Douglas R, Mosca JD, Moorman MA, Simonetti DW, Craig S, Marshak DR: Multilineage potential of adult human mesenchymal stem cells. Science 1999, 284:143-147.

15. Goldring MB, Tsuchimochi K, ljiri K: The control of chondrogenesis. J Cell Biochem 2006, 97:33-44

16. Grassel $\mathrm{S}$, Ahmed N: Influence of cellular microenvironment and paracrine signals on chondrogenic differentiation. Front Biosci 2007, 12:4946-4956.

17. Barry F, Boynton RE, Liu B, Murphy JM: Chondrogenic differentiation of mesenchymal stem cells from bone marrow: differentiation-dependent gene expression of matrix components. Exp Cell Res 2001, 268:189-200.

18. Sekiya I, Larson BL, Vuoristo JT, Reger RL, Prockop DJ: Comparison of effect of BMP-2, -4 , and -6 on in vitro cartilage formation of human adult stem cells from bone marrow stroma. Cell Tissue Res 2005, 320:269-276.

19. Weiss S, Hennig T, Bock R, Steck E, Richter W: Impact of growth factors and PTHrP on early and late chondrogenic differentiation of human mesenchymal stem cells. J Cell Physiol 2010, 223:84-93.

20. Sakaguchi Y, Sekiya I, Yagishita K, Muneta T: Comparison of human stem cells derived from various mesenchymal tissues: superiority of synovium as a cell source. Arthritis Rheum 2005, 52:2521-2529.

21. Chen FH, Tuan RS: Mesenchymal stem cells in arthritic diseases. Arthritis Res Ther 2008, 10:223.

22. Shanmugasundaram $\mathrm{S}$, Chaudhry $\mathrm{H}$, Arinzeh TL: Microscale versus nanoscale scaffold architecture for mesenchymal stem cell chondrogenesis. Tissue Eng Part A 2011, 17:831-840.

23. Vinatier C, Bouffi C, Merceron C, Gordeladze J, Brondello JM, Jorgensen C, Weiss P, Guicheux J, Noël D: Cartilage tissue engineering: towards a biomaterial-assisted mesenchymal stem cell therapy. Curr Stem Cell Res Ther 2009, 4:318-329.

24. Mahmoudifar N, Doran PM: Chondrogenesis and cartilage tissue engineering: the longer road to technology development. Trends Biotechnol 2012, 30:166-176.

25. Rada T, Reis RL, Gomes ME: Adipose tissue-derived stem cells and their application in bone and cartilage tissue engineering. Tissue Eng Part B Rev 2009, 15:113-125.

26. Wang W, Li B, Yang J, Xin L, Li Y, Yin H, Qi Y, Jiang Y, Ouyang H, Gao C: The restoration of full-thickness cartilage defects with BMSCs and TGF-beta 1 loaded PLGA/fibrin gel constructs. Biomaterials 2010, 31:8964-8973.

27. Connelly JT, Wilson CG, Levenston ME: Characterization of proteoglycan production and processing by chondrocytes and BMSCs in tissue engineered constructs. Osteoarthr Cartil 2008, 16:1092-1100.

28. Bouffi C, Thomas O, Bony C, Giteau A, Venier-Julienne MC, Jorgensen C, Montero-Menei C, Noël D: The role of pharmacologically active microcarriers releasing TGF-beta3 in cartilage formation in vivo by mesenchymal stem cells. Biomaterials 2010, 31:6485-6493. 
29. Wynn RF, Hart CA, Corradi-Perini C, O'Neill L, Evans CA, Wraith JE, Fairbairn L, Bellantuono I: A small proportion of mesenchymal stem cells strongly expresses functionally active CXCR4 receptor capable of promoting migration to bone marrow. Blood 2004, 104:2643-2645.

30. Dar A, Goichberg P, Shinder V, Kalinkovich A, Kollet O, Netzer N, Margalit R, Zsak M, Nagler A, Hardan I, Resnick I, Rot A, Lapidot T: Chemokine receptor CXCR4-dependent internalization and resecretion of functional chemokine SDF-1 by bone marrow endothelial and stromal cells. Nat Immunol 2005, 6:1038-1046.

31. Caplan Al: Adult mesenchymal stem cells for tissue engineering versus regenerative medicine. J Cell Physiol 2007, 213:341-347.

32. Niemeyer $P$, Krause $U$, Kasten $P$, Kreuz PC, Henle $P$, Südkam NP, Mehlhorn A Mesenchymal stem cell-based HLA-independent cell therapy for tissue engineering of bone and cartilage. Curr Stem Cell Res Ther 2006, 1:21-27.

33. Le Blanc K, Tammik C, Rosendahl K, Zetterberg E, Ringdén O: HLA expression and immunologic properties of differentiated and undifferentiated mesenchymal stem cells. Exp Hematol 2003, 31:890-896.

34. Tipnis S, Viswanathan C, Majumdar AS: Immunosuppressive properties of human umbilical cord-derived mesenchymal stem cells: role of $\mathrm{B} 7-\mathrm{H} 1$ and IDO. Immunol Cell Biol 2010, 88:795-806.

35. Aggarwal S, Pittenger MF: Human mesenchymal stem cells modulate allogeneic immune cell responses. Blood 2005, 105:1815-1822.

36. Murphy JM, Fink DJ, Hunziker EB, Barry FP: Stem cell therapy in a caprine model of osteoarthritis. Arthritis Rheum 2003, 48:3464-3474.

37. Grigolo B, Lisignoli G, Desando G, Cavallo C, Marconi E, Tschon M, Giavaresi G, Fini M, Giardino R, Facchini A: Osteoarthritis treated with mesenchymal stem cells on hyaluronan-based scaffold in rabbit. Tissue Eng Part C Methods 2009, 15:647-658.

38. Alfageh $\mathrm{H}$, Norhamdan MY, Chua KH, Chen HC, Aminuddin BS, Ruszymah BH: Cell based therapy for osteoarthritis in a sheep model: gross and histological assessment. Med J Malaysia 2008, 63 (Suppl A):37-38.

39. Nejadnik H, Hui JH, Feng Choong EP, Tai B-C, Lee EH: Autologous bone marrow-derived mesenchymal stem cells versus autologous chondrocyte implantation: an observational cohort study. Am J Sports Med 2010, 38:1110-1116.

40. Kuroda R, Ishida K, Matsumoto T, Akisue T, Fujioka H, Mizuno K, Ohgushi H, Wakitani S, Kurosaka M: Treatment of a full-thickness articular cartilage defect in the femoral condyle of an athlete with autologous bone-marrow stromal cells. Osteoarthr Cartil 2007, 15:226-231.
41. Wakitani S, Nawata M, Tensho K, Okabe T, Machida H, Ohgushi H: Repair of articular cartilage defects in the patello-femoral joint with autologous bone marrow mesenchymal cell transplantation: three case reports involving nine defects in five knees. J Tissue Eng Regen Med 2007, 1:74-79.

42. Haleem AM, Singergy AAE, Sabry D, Atta HM, Rashed LA, Chu CR, El Shewy MT, Azzam A, Abdel Aziz MT: The clinical use of human culture-expanded autologous bone marrow mesenchymal stem cells transplanted on platelet-rich fibrin glue in the treatment of articular cartilage defects: a pilot study and preliminary results. Cartilage 2010, 1:253-261.

43. Kasemkijwattana C, Hongeng S, Kesprayura S, Rungsinaporn V, Chaipinyo K, Chansiri K: Autologous bone marrow mesenchymal stem cells implantation for cartilage defects: two cases report. J Med Assoc Thai 2011, 94:395-400.

44. Davatchi F, Abdollahi BS, Mohyeddin M, Shahram F, Nikbin B: Mesenchymal stem cell therapy for knee osteoarthritis. Preliminary report of four patients. Int J Rheum Dis 2011, 14:211-215.

45. Centeno CJ, Busse D, Kisiday J, Keohan C, Freeman M, Karli D: Increased knee cartilage volume in degenerative joint disease using percutaneously implanted, autologous mesenchymal stem cells. Pain Physician 2008, 11:343-353.

46. Osiris Therapeutics Announces Positive One Year Data from Chondrogen Trial for Knee Repair. 2007 [http://osiris.com/pdf/PR\%2061\%2027Nov07\%20 Chondrogen\%201\%20Year\%20Data.pdf]

47. Vangsness CT, David TD, David WG, Jack F, Joel LB, John B O, David LF: A randomized clinical trial using mesenchymal stem cells for meniscus regeneration and osteoarthritis [http://www.abstractsonline.com/Plan/ ViewAbstract. aspx?mID=2841\&sKey=0f656a11-e2a1-4eda-a437a45c534ce $5 \mathrm{db} \& c K e y=3 c 940044-d a 6 e-4062-987 f-$ 66314ec7798b\&mKey=\{BA8AA154-A9B9-41F9-91A7-F4A4CB050945].

48. Pak J: Regeneration of human bones in hip osteonecrosis and human cartilage in knee osteoarthritis with autologous adipose-tissue-derived stem cells: a case series. J Med Case Reports 2011, 5:296.

49. ClinicalTrials.gov homepage [www.clinicaltrials.gov].

\section{doi:10.1186/scrt116}

Cite this article as: Gupta PK, et al.: Mesenchymal stem cells for cartilage repair in osteoarthritis. Stem Cell Research \& Therapy 2012, 3:25. 